\title{
Glycometabolic Disorders in Patients with B -Thalassemia Major in Egypt
}

G.S.Abdelmotaleb, K.M.Eid, A.M.Diab, E.S.Mostafa and E.S.Ahmed Pediatrics ,Clinical,Chemical Pathology Dept., Faculty of Medicine, Benha Univ., Benha, Egypt

E-Mail:Eman2356@gmail.com

\begin{abstract}
Beta thalassemia is one of the most common single-gene disorders that require regular blood transfusion. Repeated blood transfusions in these patients lead to the accumulation of iron in the body that result in damage to critical organs such as liver, pancreas and heart. Diabetes is one of the most common endocrine disorder worldwide that due to high prevalence and chronic nature of diabetes imposes a heavy cost on health care systemTherefore this study aimed to assess prevalence of insulin resistance in beta thalassemia major. This study included 40 B-thalassemia major patients on regular blood transfusion ,age range 6-20 years and 40 control.Detailed history was taken about units of blood transfusion and chelation therapy.clinical examination included liver and spleen size. Laboratory investigations were done in the form of serum ferritin,fasting plasma insulin ,fasting and $2 \mathrm{hrs}$ post prandial plasma glucose.Insulin resistance was calculated using Homeostasis Model Assessment of insulin resistance (HOMA-IR) .Our results showed that $8 \%$ of thalassemic patients had insulin resistance.There was no statistical significance between insulin resistance, units of blood transfusion and serum ferritin.conclosion:insulin resistance is common in patients of beta thalassemia major and regular follow up of blood sugar is recommended.
\end{abstract}

Key words: Glycometabolic, B-thalassemia , Egypt.

\section{Introduction}

In Egypt, thalassemia is the most common hemolytic anemia with carrier rates ranging from 9 to $16 \%$. Thalassemia causes a severe hemolytic anemia in patients necessitating frequent transfusions leading to iron overload and endocrine complications [1]. Diabetes is an important problem encountered in thalassemic patients.

The IR asalonglasting subclinicalstatecan also be detected in otherdisorders, andits early detectionis generally recommended .Boththeimproved life expectancy andthe highprevalence of diabetes mellitus in secondary hemosiderosis highlight IR screening in Btm [2].

Different methods have been introduced for IR assessment. The gold standard method is euglycemic clamp, but it is invasive, requires expert staff, and has very limited clinical indications.Thus, other alternative non-invasive indirect indices for IR risk assessment are introduced.The homeostasis smodel assessment of insulin resistance(HOMA) is among the more commonly used IR surrogate [3].

\section{Material and methods \\ 2.1.Material}

This study was conducted on 40children with $\beta$ thalassemia major, age between 6-20years ,on regular blood transfusion and 40 normal children,age and sex matched as controls.Informed consent of parents of both cases and controls was taken .

The study was a, PP.roved by the ethical committee , Benha University, faculty of medicine. Patient suffering from any liver disease and previously diagnosed as a case of diabetes mellitus, were excluded.

\subsection{Methods}

Detailed history was taken about units of blood transfusion, details of chelation therapy and clinical examination was done including liver and spleen size. Laboratory investigations were done in the form of Serum ferritin,liver enzymes ;alanine aminotransferase(ALT), aspartate aminotransferase(AST) were done by( Biosystem A 15 autoanalyzer).Fasting plasma insulin level measure ,Fasting and $2 \mathrm{hrs}$ post prandial plasma glucose were done by (Glucose TR, SPINREACT), Fasting plasma glucose was obtained after $8 \mathrm{hrs}$ of fasting ,at the same time blood for fasting plasma insulin level was collected, then after taking a meal, $2 \mathrm{hrs}$ post prandial plasma glucose was obtained .

Evaluation of insulin resistance index using the Homeostasis Model Assessment (HOMA). [Insulin Resistance Index (HOMA-IR) = (fasting plasma glucose $(\mathrm{mmol} / \mathrm{L}) \quad \mathrm{X}$ fasting plasma insulin $(\mu \mathrm{u} / \mathrm{mL})) /$ 22.5]. HOMA-IR value of $\geq 2.7$ was considered to be an indicator of insulin resistance.

\subsection{Statistical methods}

The collected data were tabulated and analyzed using SPSS version 16 software (SpssInc, Chicago, ILL Company). Categorical data were presented as numbers and percentages, Chi square $\left(\chi^{2}\right)$ and Fisher's exact tests were used to analyze them. Quantitative data were tested for normality using Shapiro-Wilks test assuming normality at $\mathrm{P}>0.05$. Normally distributed variables were expressed as mean \pm standard deviation and analyzed by St." $t$ " for 2 independent groups, while non parametric data were presented as median and inter-quartile range (IQR), and analyzed by Mann Whitney $\mathrm{U}$ test $\left(\mathrm{Z}_{\mathrm{MWU}}\right)$ test. [4].

\section{Results}

Our study included 40 patient of thalassemia and 40 controls of the same age and sex,thalassemic patients in our study included 26 males and 14 females , and controls group included 17 males and 13 females.all patients of thalassemia were on chelation therapy $50 \%$ on deferasirox ,25\% on deferiprone, $25 \%$ on combined deferasirox and deferiprone.there was significant increase in $\mathrm{CBC}$ parameters in patients than controlsTable (1) there was significant difference in liver enzymes between patients and control. there was significant increase in HOMA-IR 
in patients than control. In our study $8 \%$ of thalassemic patients had insulin resistance and none of the controls group had insulin resistanceTable (2). Prevalence of insulin resistance wasn't increased with increase age ,duration of blood transfusion and showed no increase of fasting plasma glucose,2hrs, PP. glucose and ALT in patients than control.no correlation between serum ferritin and HOMA-IR Table (3).

Table(1) CBC parameters of patients and controls.

\begin{tabular}{|c|c|c|c|c|c|c|c|c|}
\hline \multirow[t]{2}{*}{ Variable } & \multicolumn{3}{|c|}{$\begin{array}{c}\text { Patients } \\
(\mathrm{N}=40)\end{array}$} & \multicolumn{3}{|c|}{$\begin{array}{c}\text { Controls } \\
(\mathrm{N}=30)\end{array}$} & \multirow[t]{2}{*}{ St."t"” } & \multirow[t]{2}{*}{$\mathbf{P}$} \\
\hline & Mean & \pm SD & Range & Mean & \pm SD & Range & & \\
\hline Hb\% & 8.49 & 1.15 & $6.3-10.0$ & 10.68 & 1.34 & $8.4-13.0$ & 7.34 & $<0.001(\mathrm{HS})$ \\
\hline MCV & 69.4 & 5.79 & $55-80$ & 76.6 & 7.46 & $63-86$ & 4.53 & $<0.001$ (HS) \\
\hline МСH & 27.1 & 3.92 & $20-33$ & 30.7 & 3.51 & $23-36$ & 4.05 & $<0.001(\mathrm{HS})$ \\
\hline WBCs & 8.51 & 2.73 & 4-12 & 9.66 & 3.88 & $4.5-20$ & 1.44 & $0.15(\mathrm{NS})$ \\
\hline PLTs & 290.6 & 141.3 & $123-831$ & 288.8 & 107.5 & $143-500$ & 0.061 & 0.95 (NS) \\
\hline
\end{tabular}

Table(2) Insulin resistance in patients group.

\begin{tabular}{|c|c|c|c|c|c|}
\hline & & & \multicolumn{2}{|c|}{ Group } & \multirow[t]{2}{*}{ Total } \\
\hline & & & Patients & Controls & \\
\hline \multirow[t]{4}{*}{ IR } & No & Count & 32 & 40 & 72 \\
\hline & & $\%$ within Group & $12.8 \%$ & $100.0 \%$ & $57.6 \%$ \\
\hline & Yes & Count & 8 & 0 & 8 \\
\hline & & $\%$ within Group & $3.2 \%$ & $.0 \%$ & $6.4 \%$ \\
\hline \multirow[t]{2}{*}{ Total } & & Count & 40 & 40 & 80 \\
\hline & & $\%$ within Group & $100.0 \%$ & $100.0 \%$ & $100.0 \%$ \\
\hline
\end{tabular}

Table(3)correlation between HOMA-IR and serum ferritin.

\begin{tabular}{lcc}
\hline With & \multicolumn{2}{c}{ HOMA-IR } \\
\cline { 2 - 3 }$(\mathbf{n = 4 0})$ & Pho \\
\cline { 2 - 3 } Age & 0.291 & 0.068 \\
Duration of blood transfusion & 0.086 & 0.56 \\
Weight (kg) & 0.087 & 0.59 \\
Height (m) & 0.129 & 0.42 \\
BMI (kg/m $\left.{ }^{2}\right)$ & 0.005 & 0.97 \\
Liver size & 0.031 & 0.85 \\
Spleen size & -0.051 & 0.76 \\
Hb & 0.146 & 0.37 \\
MCV & -0.061 & 0.71 \\
MCH & -0.027 & 0.87 \\
WBCs & 0.002 & 0.99 \\
PLTs & 0.289 & 0.07 \\
ALT & 0.002 & 0.99 \\
AST & 0.124 & 0.44 \\
Serum ferritin & 0.289 & 0.07 \\
Fasting plasma glucose & 0.027 & 0.87 \\
Fasting plasma insulin & 0.007 & 0.98 \\
2hrs , PP. plasma glucose & 0.027 & 0.123 \\
\hline
\end{tabular}

\section{Discussion}

Iron overload resulting in diabetes mellitus which is one of the major complications of chronic transfusiondependent B- thalassemia major and it may be missed unless looked for, and can even present as an acute emergency like diabetic ketoacidosis[5].

It can occur due to impairment of insulin secretion or due to insulin resistance[6]. thalassemic patients in this study had microcytic hypochromic anemia with significant increase in them than the controls. this was due to the nature of thalassemia as the gene defects in B-thalassemia major resulted in anemia and microcytosis[7]. In our study there was also significant increase in liver functions (ALT,AST) in patients of thalassemia than control group, as patients with $\beta$-thalassemia major need life-long transfusions.A common clinical problem in these patients is iron 
overload and its toxicity to different organs escpecially the liver. [8]

Our study showed that (8\%)

of patients of B-thalassemia major had insulin resistance , and none of the control group had insulin resistance. This is similar to that reported in a study on Chinese children with B-thalassemia major that insulin resistance was significantly higher in B-TM cases than the controls group[9].our results showed that prevalence of insulin resistance wasn't increased with increase age ,duration of blood transfusion and showed no increase of fasting plasma glucose, $2 \mathrm{hrs}$, PP. glucose and ALT in patients than control in contrast to [10] who found that There was a progressive increase IR with the increase in the number of units transfused and age.our results showd that no correlation between serum ferritin and HOMAIR,in contrast to [11] who found that the association between serum ferritin values and HOMA-IR index value was highly statistically significant $(\mathrm{P}<0.001)$. This indicates that at higher serum ferritin levels, HOMA-IR values were above the cutoffs, suggesting the presence of insulin resistance.

\section{Conclusion}

Insulin resistance is common in B-Thalassemia major with recurrent blood transfusion.and these patients should monitored periodically by HOMA-IR index.

\section{References}

[1] M. Toumba, A .Sergis, C .Kanaris, N.Skordis, Endocrine complications in patients with Thalassaemia Major. Pediatr Endocrinol Rev, Vol.5,, PP.642-8,2007.

[2] R. Chatterjee, R.Bajoria ,New concept in natural history and management of diabetes mellitus in thalassemia major. Hemoglobin, Vol.33(1), , PP.. 127-30,2009.

[3] A.Borali, C.Livingstone, I.Kaddam, G.Ferns,Selectionofthea, PP.ropriate method for the assessment of insulin resistance. BMC MedResMethodol, Vol.11, , PP..158-68,2011.

[4] CR Khothari ,Research Methodology: Methods and Techniques, New Age International, New Delhi;2004.

[5] J. P. Kushner, J. P. Porter , N. F. Olivieri ,Secondary iron overload.Hematology Am Soc Haematol Educ Program, Vol.5(3), , PP..47-61,2001.

[6] M. Hafez , I. Yousry , F. Abdel Hamed ,abnormal glucose tolerance in B-thalassemia major. Hemoglobin, Vol.33 (2), , PP..101-108,2009.

[7] J.R. Herbert , M.D. James, Alpha and Beta Thalassemia. Am Fam Physician. 15, Vol.80(4), , PP..339-344,2009.

[8] R. Taghizadeh, B .Moradveisi, F .Kompany ,Correlation between Heart and Liver Iron Levels Measured by MRI T2* and Serum Ferritin in Patients with $\beta$-thalassemia Major. Int J Pediatr, Vol. 4 (3), , PP..1559-67,2016.

[9]Y. Liang ,R. Bajoria ,Y. Jiang, Prevalence of diabetes mellitus in Chinese children with thalassaemia major.Tropical Medicine \& International Health; , Vol.22(6), PP..716-724,2017.

[10] K.G. Bhat , P. K. Periasamy , Effect of long-term transfusion therapy on the glycometabolic status and pancreatic beta cell function in patients with beta Thalassemia major. J Fam Med Primary Care, Vol.3, , PP..119-23,2016.

[11]A. M. Ansari ,K. G. Bhat, S. S. Dsa , study of insulin resistance in patients wiyh B-thalassemia Major patients and validity of TYG index.J Pediatr Hematol Oncol, Vol.40(2), , PP..128-131,2018. 